\title{
Employee turnover and employee performance: a comparative study among nurses
}

\begin{abstract}
This descriptive research study has been undertaken in Tirunelveli city, Tamilnadu to foresee and differentiate perception of the nurses working in multi-speciality and single speciality hospitals towards the impact of employee turnover on performance of existing nurses. The study has sampled 120 nurses (60 from multi and 60 from single speciality hospitals) qualified with Diploma in General Nursing and Midwifery (DGNM) and Bachelor in Nursing (B.Sc Nursing) courses using judgement sampling technique. The analysed primary data collected through a constructed questionnaire has found that nurses working in single speciality hospitals have shown higher perception towards work load, work time, loss of interest, work stress and inability to provide information than multi-speciality hospitals. Nurses working in both kinds of hospitals have shown equal perception towards health related problems, conflict and dispute, sense of commitment and morale. Nurses who are working in both kinds of hospitals with the characteristic of married, less than 30years of age, drawing less than Rs.8000 salary and having less than 2years of work experience have shown high perception towards impact of employee turnover on performance of existing nurses.
\end{abstract}

Volume I Issue 5 - 2017

\author{
Rajan D \\ Department of Business Administration, West Africa
}

Correspondence: Rajan D, Lecturer and Head, Department of Business Administration, Blue Crest College,Accra, Ghana, West Africa, Email drdirajan@gmail.com

Received: November 20, 2017 | Published: December 07, 2017

Keywords: nurse, employee turnover, employee performance, multi-speciality hospital, single-speciality hospital, tirunelveli city

\section{Introduction}

\section{Background of the study}

An organization's success depends mainly on employee retention, which will help the organizations reduce employee's job turnover and increasing organizational effectiveness. ${ }^{1}$ Employee turnover which has attracted major attention in this current century, to some extent, is fundamentally needed for growth of any organization. Advancement and changes taking place very rapidly in life styles, culture, technology, economy and legal aspects have become the major causative factor of employee turnover. Off all these factors, economical changes in the country and increased needs and wants of money are the most important factors being responsible for employee turnover. Among the technical and middle level employees, need for career advancement remains a very challenging factor in these highly prevalent competitive and unemployment industries.

Employee turnover remains positive in some situations but not in all situations. When non-productive employee leaves, the impact will be positive. It will give the opportunities for other workers who really have superior skill level and it will give opportunity for the management to increase diversity, streamline and regulate budget. At the same time, workers are laid off either openly or secretly on daily basis and the high level of turnover poses a serious problem for the industry especially if the separation is voluntary by relatively high profile numbers of human capital value. ${ }^{3}$ Nursing, the backbone of the hospital industry is one of the paramedical departments being superiorly responsible for preventive and promotive care of the patients. They carry out multiple tasks that are inevitable for recovery of the patients from disease and surgery. They check vital signs, get consent from the patients, provide them medicines, and prepare them when the patients undergo surgical treatment. After the treatment and surgery are done, when the patients are shifted to intensive care unit or other wards they carry out their functions in the form of checking vital signs, providing medicines, feeding foods, positioning and rotating the patients and writing up the patients' conditions in the case sheet at frequent intervals, attending the doctors' visits, and taking notes of their instructions and carry out them and also explaining about the patients' conditions to their relatives and attendees whenever they request.

In order to carry out these tasks completely and effectively, adequate number of nursing personnel should exist in nursing department. Adequate number of nursing employees should exist with right mixture of both senior and junior nurses so that junior nurses can work under the guidance of senior nurses. Moreover, the work environment must be very conducive for nursing personnel so as to work peacefully and satisfactorily. When the work environment is not perfect and when so much deficiency exists in both the work processes and system, it will lead to employee turnover since nurse deal with various natures of the patients and they stand for longer time as part of their work and they deal with various crisis situations. The study area, Tirunelveli city has attained abundant growth in health care aspect. Hospitals, diagnostic centres and pharmaceuticals are increasing very rapidly year by year as other manufacturing industries. But employee turnover of the nurses also is equally increasing. There are number of reasons for employee turnover in the study area. Human resource management practice has not yet grown up richly. Still, in many hospitals, 12hours duty with two shift working system, less pay and that is not according to the government norms, poor welfare facilities and poor concern over career development of the employees and training and development practices and rigid leadership system are highly practices throughout the district. These are some of the important factors causing employee turnover among nurses. Employee turnover of the nurses affect the existing nurses severely. Hence, it is 
needed to explore to what extent employee turnover of nurses affect job performance of the existing nurses. Hence, the present research is undertaken in the study area as a comparative study to understand and differentiate perception of nurses working in private multi-speciality and single speciality hospitals towards impact of employee turnover on performance of existing nurses.

\section{Need for the research}

Nurses have major role in deciding satisfaction and safety of the patients. Adequate number of nurses in terms of educational qualification and experience is required for smooth functioning of the hospitals. Both satisfaction and safety of the patients depends on how productively the nurses contribute their work towards the patients. When adequate nursing personnel exist in the department according to the work load and number of patients, the contribution given by the nurses would be productive. When the nursing employees are not adequate in number according to the number of the patients, the work load to each nurse will increase which affect not only their performance in work but also weaken their health. Employee turnover among nurses remain quite common in both multi-speciality and single speciality hospitals. As majority of the nursing employees in all hospitals are females, employee turnover commonly and highly exists because of marriage, pregnancy, delivery, higher studies and transfer of the husbands are some of the reasons.

At the same time, filling vacant place remains the most important task for the hospital management to enable smooth functioning of the department and reduce high work burden of the nurses. When delay occurs to fill the vacant positions, the work load to the existing nurses would increase which paralyse performance of the existing nurses. As most of nursing tasks are highly technical oriented, the work of staff nurses cannot be replaced by nursing assistants. Hence, the existing staff nurses alone need to perform the all works of nursing procedures. It increases their work load causing tiredness, stress and dissatisfaction which further affect their attention on the work. When attention gets deviated because of too much work load and stress, they may forget to do their vital functions which will further affect satisfaction and safety of the patients. When satisfaction and safety of the patients is affected, it will paralyse reputation of the hospitals. Hence, it is the primary job of both multi-speciality and single speciality hospitals to understand how employee turnover affect the remaining staff nurses and take necessary steps to prevent the employee turnover. In view of this concept, the present study has been undertaken in the study area with the objectives of identifying and differentiating impact of employee turnover on performance of the existing employees.

\section{Scope of the study}

This present research has focused nurses working in private multispeciality and single speciality hospitals in Tirunelveli city. Nurses qualified with BSc Nursing and Diploma in General nursing and Midwifery (DGNM) has been covered in this research. The impact of voluntary and involuntary turnover of nurses on performance of existing nurses has been analysed in this present study.

\section{Significance of the study}

The result of this study will assist the hospital management and other similar organizations to understand how employee turnover of nurses paralyse performance of the existing nurses. Thus, it enables the hospitals to formulate suitable policies with respect to retention of the potential employees and reduction of employee turnover of nur- ses. The findings of the study can be used as secondary data for future study.

\section{Profile of the study}

This study has been undertaken in Tirunelveli city. Tirunelveli also known as Nellai and Tinnevelly is a city in the Indian state of Tamil Nadu. It is the head quarter of the Tirunelveli District and it is located 700 kilometres southwest of the state capital, Chennai, Tamilnadu. As of 2011, census of India, Tirunelveli has a total population of 474,838. Males constitute $49 \%$ of the population and females $51 \%$.

\section{Objectives of the study}

The objectives of this research are as follows.

a. To foresee and differentiate impact of employee turnover on performance of existing nurses

b. To understand and compare the impact of employee turnover on performance of the existing nurses on the basis of demographic characteristics

c. To offer suitable suggestions to control employee turnover

\section{Review of literature}

\section{Definition}

According to, ${ }^{4-6}$ 'Turnover is the individual movement across membership boundary of an organization and it is the ratio of the employees of organization who left in a particular period of time with the average number of employees in that organization during the same period of time. Currivan $\mathrm{DB}^{7}$ quoted it is a behaviour which describes the process of leaving or replacing employees in an organization and it is the ratio of number of workers that had to be replaced in a given time period to the average number of workers. ${ }^{8}$

\section{Previous studies related to employee turnover}

Analysed perception of nurses towards push and pull factors of nurses turnover from the samples of 60 nurses working in private multi-speciality hospitals in Tirunelveli city, Tamilnadu. ${ }^{9}$ The study identified that inadequate salary and it is not in par with work load and contribution, two shift work system with long and unsocial working hours, high work load which is due to inadequate staff nurses and other supportive staffs in accordance with volume of the patients, absence of accommodation facilities and inadequate safety, allocation of ward which is unfit for health and the ward which is not interested and insufficient salary hike and it is not uniform in nature were the foremost push factors of turnover of nurses. Moreover, the study also identified that high salary, location of the hospital, three shift work system, eight hours duty, less work load and it is uniform for all staffs, accommodation facilities and qualified in charge (nursing superintendent) who is in same nursing profession were the foremost pull factors of turnover of nurses. The analysis of the study showed that the perceptions of respondents towards push factors of turnover of nurses were at medium level and their perception towards pull factors of turnover of nurses was at high level.

Namasaka David Butali et al. ${ }^{10}$ studied the effects of staff turnover on the employee performance of work at Masinde Muliro University of Science and Technology. The objectives of the study were to identify financial or economic effects of staff turnover. The result of the study indicated that staff turnover had negative financial effects 
on the organization and staff turnover negatively affected the social set up of an organization. The study indicated in the result area that the majority of the respondents have indicated that employee turnover increased the work for remaining staff, affected customer satisfaction, decreased income due to reduced productivity, lowers productivity in the organization, increased liability to practice and lower the morale of the employees. The study recommended that management should improve the terms and conditions of services to increase on the staff retention rate so as to avoid liabilities caused by staff turnover.

Rajan D et al. ${ }^{11}$ in his study found that excessive work load for remaining staff, delay in daily routine procedures, poor patient satisfaction, complaints from patients, poor job satisfaction of the remaining nurses, complaints from medical personnel about delay in routine procedure and incomplete procedure, complaints from housekeeping and biomedical department in terms of segregation of biomedical wastes and wastages and loss of resources as newly joined staff has not known the routines well are the foremost impact of turnover of nurses on organization performance. The study also found that increased recruitment cost, increased training cost, impaired patient safety, high stress among remaining nurses as they have to do the duties of newly joined nurses also until they learn the routine work, difficulty to manage the hospital when turnover occur during festival time, high leave and absenteeism of remaining nurses, sickness among remaining nurses because of heavy work load and preference of the patients to next hospital because of poor nursing care are the next foremost impact of turnover of nurses on organization performance.

The study advocated that impairment of reputation of the hospital name when the senior and capable staff are absent, impaired quality of care, low level of efficiency of the new staff nurses recruited, disturbed flow of work, damage and failure of equipments because of lack of knowledge of new staffs, poor morale of the employees, conflict among existing staffs because of lack of nurses and work overload and minor injuries because of high work load and tiredness are the least impact of turnover of nurses on organization performance, ${ }^{12}$ studied employee turnover in banking sector. The objectives of the study were to identify the key factors of the employee turnover and determine the extent to which the identified factors are influencing employee's turnover. The turnover rate has analysed based on three variables namely work environment, career development and job satisfaction. The result of the study indicated that work environment, job stress, compensation, employee relationship with management, career growth had significantly influenced the employee turnover in banking sector. The result of the study has proved that job satisfaction and work environment were the prime factors for employee turnover. Comparative to job satisfaction and work environment, career development had less but a quiet considerable significance. The study also indicated that high turnover rate had a negative impact on an organization performance.

Jhatial et al. ${ }^{13}$ in their study revealed that overall picture of HRM and organization culture in public sector organizations was poor whereas private organization was comparatively better improving. They also said that the respondents in MNCs had expressed high agreement on merit based HRM, organizational culture and attitude of business with high self-esteem. The study highlighted that there was inter relationship among all the variables and the study concluded that taking care of human factor with mutual respect, mentoring and employee empowerment could enhance employee morale, commitment and satisfaction which virtually linked employee's decision to stay in the organization. ${ }^{14}$ Found job dissatisfaction, unfavourable working conditions, long working hours with minimal pays and poor employees training programs were the causes of turnover. The study also reported that un conducive work conditions resulted to the employees developing work related stress and reduced employees' organizational commitment. The result explained that few hotels had employees who worked up to their retirement and the study observed employee resignation was the major form of labour wastage in both these type of hotels. The findings showed that most of the respondents were familiar with the vision and mission statement of the organization they were working with. The result emphasized that the employees had not involved in decision making process even those decisions which affected their jobs and it resulted to the main causes of resignation in the hotels under the study. Employers were found inflexible and they did not provide a balance between work and employees' personal life. Therefore, majority of the respondents reported that they did not know whether they utilised their ability and skills.

Abdali $\mathrm{F}^{15}$ in his study demonstrated that only professional qualification of the employees may be higher intentions of turnover in these organizations, while age, level of education, tenure in the organization, level of income had not impact the causes of turnover in employees of computer graphic sectors of Karachi, Pakistan. The study explained that there was a significant difference between the strategies of younger and older employees of CG companies of Karachi-Pakistan in order to control employee turnover for the sustainable growth of organization. The findings proved that younger age employees of computer graphic sectors of Karachi Pakistan may think the retention strategies for employees in different ways as compare to older age employees.

Chalkiti $\mathrm{K}^{16}$ Revealed that staff turnover levels differ across tourism jobs at various organizational levels. The study found that relative to managerial level jobs, operational level jobs also demand lower job specialization, skills and offer limited job progression opportunities. Hence, the higher levels of staff turnover were found in operational jobs as they directly had contact with customers and it made them more susceptible to emotions and burnout. Respondents from insular regions reported seasonality to be a significant factor causing staff turnover than respondents from peninsular regions. Respondents from both insular and peninsular regions also considered job satisfaction; career development, working hours, emotional labour, social work relations and unsocial working conditions had a neutral effect on staff turnover. It could be noted that the largest proportion of Greek tourism enterprises had represented family owned and operated firms, whereby the type and interdependency of social or work relationship was unimportant.

Shah et al. ${ }^{17}$ studied factors significantly intending the employees to quit job. The results said that among the push factors, the respondents agreed 3 factors namely family related problems, not liking their boss and their expectation has not been fulfilled were the most important push factors causing turnover. The most significant pull factors which made their intention to quit the job were good location of other organisations, higher education opportunities, good children education, organization support and reputation of pull organization. The most significant factors which contributed in turnover intentions were family living in other area and health related problems. The other factors which significantly contributed in turnover intentions were social status, children education, fun and unable to follow 
organization rules. Pull factors were not significantly contributed in the turnover intention. The overall conclusion was that personal factors were more significant in turnover intention of University teacher in Pakistan. Shamsuzzoha and Rezaul Hasanshumon (2008) studied actual reasons of turnover and its negative effects among the local industries in Bangladesh. The results of the study proved that turnover rate is higher than government sector due to job insecurity. The study explained that less salary, irregular payments, improper management, better job options, job location, noisy work environment, job insecurity, behaviour at root level, job dissatisfaction, delay of promotion insufficient medical allowance, leaving tendency of people, working time, less increment were the causes of turnover. Security of the job, pension, good location, increment, better salary structure, good working environment and good behaviour of top management had been mentioned as some of the reasons why employees stayed in the organization.

Kayuni $\mathrm{H}^{18}$ in their study found that poor salaries, incentives and poor working conditions, loss of status of teacher, indiscreet reforms and loss of motivation, stress, poor recruitment and selection practices, unfair measures of performance, poor housing and school infrastructure, high death rate due to illness but no medical scheme, frequent changes in the syllabus and education system, lack of administrative support system, poor recruitment and training programs were the causes of turnover of teachers in Malawi ministry of education.

Ramball Sunil et al. ${ }^{19}$ studied the employees' decisions to remain employed at a particular organization and possible reasons for choosing to leave. The result showed that locations of the company, compensation, the job itself, the company's reputation, career development, job security, organizational culture, challenge, training and development, empowerment, attractive benefits were the reasons for choosing the corporation as an employer. The study found that salary, lack of challenge and opportunity, lack of career advancement opportunities, lack of recognition, ineffective leadership, inadequate emphasis on teamwork, not having the opportunity for a flexible work schedule, too long of a commute, lack of trust in senior management, inadequate opportunities for training and development, low overall satisfaction were the reasons why the employees leave the job from the existing organizations.

Rajan D et al. ${ }^{20}$ studied how employee turnover impact employee performance of existing nurses working in private multi-speciality hospitals in Tirunelveli city and found that excessive workload for the existing nurses, inability to leave the duty on time, healthrelated problems, inability to provide adequate care and equal importance for all patients, conflict and dispute with co-workers and other departmental workers, inability to take decision and solve problems that arises suddenly, inability to segregate biomedical wastes according to the rules were the foremost impact. The study also found that inability to complete daily routines and procedures on time and make delay, inability to provide the patients adequate information about their treatment protocols and clarify their doubts clearly, high stress, inability to complete the work perfectly and keep work pending, getting minor injuries, disturbed flow of work, inability to provide adequate information to the doctors and surgeons and inability to maintain smooth relationship with the patients, their relatives and other staffs were the next foremost impact of employee turnover of performance of existing employees. The study also found that inability to use the resources fully and also wasting resources, inability to maintain and manage equipment, inability to complete record work and treatment protocols completely and commit errors in them, low level of efficiency among the existing staff nurses, often making delay in daily routine procedures, loss of interest and dissatisfaction in the job and low sense of commitment and morale were the least impact of employee turnover on performance of existing employees.

It can be known from the reviewed literatures that the studies undertaken in the study area have talked about how employee turnover impacted employee performance of nurses working in private multispeciality hospitals and how employee turnover impacted organization performance. The previous study undertaken in the study area has focused nurses working in private multi-speciality hospitals. It did not focus nurses working in single speciality hospitals. Therefore, gap exists to study how employee turnover impact employee turnover of nurses working in single speciality hospitals. Hence, the present research has been undertaken focusing nurses working in single speciality hospitals.

\section{Research methodology}

This survey based quantitative research study has adopted descriptive research design. The nurses working in private multispeciality hospitals and single speciality hospitals in Tirunelveli city are the population of this research study. A total of 120nurses (60 from single speciality and 60 from multi-speciality hospitals respectively) qualified with Diploma in General Nursing and Midwifery (DGNM) and Bachelor in Nursing (B.Sc Nursing) courses have been sampled using judgement sampling. The primary data have been collected using structured self-made questionnaire. The questionnaire consisted of two sections namely section 'A' that spoke about profile of the respondents and section ' $\mathrm{B}$ ' that elaborated impact of employee turnover on performance of the existing nurses. The questionnaire had been constructed based on Likert's five point scales namely strongly agree, agree, no opinion, disagree and strongly disagree that carried the values of 5, 4, 3, 2 and 1 respectively. The researcher discussed with nurses, administrators of the hospital, nursing superintendents (in charge) and doctors before constructing the questionnaire to obtain details about the impact of turnover on performance of the existing nurses. Secondary data have been collected from journals, books and websites to provide appropriate significance for the study. The researcher has used percentage method to analyse profile of the respondents. The researcher has used mean and standard deviation to analyse and differentiate the impact of employee turnover on employee performance.

\section{Results and discussion}

\section{Analysis and results}

It can be understood from Table 1 that among the respondents of multi-speciality hospitals, $8.33 \%$ were male and $91.67 \%$ were female. Of them, $18.33 \%$ were below 25 years of age, $43.33 \%$ between 25 and 30 years, $23.33 \%$ between 30 and 35 years and $15 \%$ were above 35 years of age. Furthermore, among them, $86.67 \%$ were married and $13.33 \%$ were unmarried. Of them, $88.33 \%$ were qualified with DGNM and $11.67 \%$ were qualified with B.Sc in Nursing. In all, $23.33 \%$ had below 2 years of work experience, $43.33 \%$ between 2 and 4 years, $20 \%$ between 4 and 6 years and $13.33 \%$ had above 6 years of work experience. Among them, 25\% were drawing below Rs. 6000 
of salary, $46.67 \%$ between Rs. 6000 and $8000,16.67 \%$ between Rs. 8000 and 10000 and $11.67 \%$ of them were drawing above Rs. 10000 of salaries. It can be known from Table 1 that among the respondents of single-speciality hospitals, $3.33 \%$ were male and $96.67 \%$ were female. Of them, $20 \%$ were below 25 years of age, $46.67 \%$ between 25 and 30 years, $26.67 \%$ between 30 and 35 years and $23.33 \%$ were above 35 years of age. Furthermore, among them, $88.33 \%$ were married and $11.67 \%$ were unmarried. Of them, $98.33 \%$ were qualified with DGNM and $1.67 \%$ was qualified with B.Sc in Nursing. In all, $16.67 \%$ had below 2 years of work experience, $38.33 \%$ between 2 and 4 years, $21.67 \%$ between 4 and 6 years and $23.33 \%$ had above 6 years of work experience. Among them, 26.67\% were drawing below Rs. 6000 of salary, $51.67 \%$ between Rs. 6000 and $8000,11.67 \%$ between Rs. 8000 and 10000 and $10 \%$ of them were drawing above Rs. 10000 of salaries.

Table I Profile of the respondents

\begin{tabular}{|c|c|c|c|c|c|c|}
\hline S. No & Measure & Description & Frequency & Percentage & Frequency & Percentage \\
\hline \multirow{2}{*}{ I } & \multirow{2}{*}{ Sex } & Male & 5 & 8.33 & 2 & 3.33 \\
\hline & & Female & 55 & 91.67 & 58 & 96.67 \\
\hline \multirow{4}{*}{2} & \multirow{4}{*}{ Age } & Below 25 years & 11 & 18.33 & 12 & 20 \\
\hline & & Between 25 and 30 years & 26 & 43.33 & 28 & 46.67 \\
\hline & & Between 30 and 35 years & 14 & 23.33 & 16 & 26.67 \\
\hline & & Above 35 years & 9 & 15 & 14 & 23.33 \\
\hline \multirow{2}{*}{3} & \multirow{2}{*}{ Marital Status } & Married & 52 & 86.67 & 53 & 88.33 \\
\hline & & Unmarried & 8 & 13.33 & 7 & 11.67 \\
\hline \multirow{2}{*}{4} & \multirow{2}{*}{ Educational Qualification } & DGNM & 53 & 88.33 & 59 & 98.33 \\
\hline & & B.Sc Nursing & 7 & 11.67 & I & 1.67 \\
\hline \multirow{4}{*}{5} & \multirow{4}{*}{ Year of working experience } & Below 2 year & 14 & 23.33 & 10 & 16.67 \\
\hline & & Between 2 and 4 years & 26 & 43.33 & 23 & 38.33 \\
\hline & & Between 4 and 6 years & 12 & 20 & 13 & 21.67 \\
\hline & & Above 6 years & 8 & 13.33 & 14 & 23.33 \\
\hline \multirow{4}{*}{6} & \multirow{4}{*}{ Salary } & Below 6000 & 15 & 25 & 16 & 26.67 \\
\hline & & Between 6000 and 8000 & 28 & 46.67 & 31 & 51.67 \\
\hline & & Between 8000 and 10000 & 10 & 16.67 & 7 & 11.67 \\
\hline & & Above 10000 & 7 & 11.67 & 6 & 10 \\
\hline
\end{tabular}

It could be understood from Table 2 that nurses working in single speciality hospitals have shown higher perception than nurses working in multi-speciality hospitals toward the factors, excessive work load for the existing nurses (V1), difficult to leave from the duty on time (V2), inability to provide adequate care and equal importance for all patients (V4), need to perform multiple works at the same time (V5), facing interruption in daily work flow (V8), loss of interest and dissatisfaction in the job (V9), inability to segregate biomedical wastes according to the rules (V11), inability to provide adequate information to the doctors and surgeons about the patients and their conditions (V13), inability to take decision and solve problems that arises suddenly because of too much work load and stress (V14), often facing minor injuries, disturbed flow of work and it affects safety of the patients (V15), high level of stress as existing nurses should carry out the duties of left nurses until new nurses are appointed in the department (V17), inability to maintain and manage equipments properly and safely because of hurriedness (V21), inability to maintain inventory accurately and to keep the things in order (V22), inability to provide the patients adequate information about their treatment protocols and clarify their doubts clearly (V23).

As far as single speciality hospitals, the manpower is less than multi-speciality hospitals. Hence, in the situation in which there is less manpower, when employee turnover happen, it will have dramatic impact on the existing employee. In most of the single speciality hospitals, only one nurse is appointed in the ward per shift along with one nursing assistant. The staff nurses need to look after all patient related work, clerical work and administrative work also. Whereas, in multi-speciality hospitals, two staff nurses are appointed along with two nursing assistants. Under this circumstance, when employee turnover happen, the nurse in the department is compelled to look after both night and day shifts continuously until new nurse is appointed. Moreover, if the existing nurse is suffered with health related issues, the routine work of the department will get paralysed dramatically. Though new nurse is appointed immediately, she may take some time to learn routine work of the department. Till that time, the existing nurse cannot leave the duty on time. Moreover, in single speciality hospitals, staff nurses have more responsibilities than multi-speciality hospitals. In multi-speciality hospitals, the staff nurses delegate some of the work such as looking after inventory management, maintenance of medical equipments and collecting records of the patients and moving the patients to other wards. But, in single speciality hospitals, staff nurses need to do all these works. As a result, their work load increase and their concentration on work get diminished which impair their performance on work. Virtually, when work load increases and concentration detracts, they get so much stress which gets them to 
make mistakes in their work processes and affect their interpersonal relationship with other employees in the department and other departments also. This kind of activities of nurses will impact on satisfaction and safety of the patients negatively.

Table 2 Impact of employee turnover

\begin{tabular}{|c|c|c|c|c|c|c|c|c|c|c|}
\hline \multirow{3}{*}{ Employee performance } & \multicolumn{5}{|c|}{$\begin{array}{l}\text { Multi-Speciality } \\
\text { Hospitals }\end{array}$} & \multicolumn{5}{|c|}{ Single Speciality Hospitals } \\
\hline & \multirow{2}{*}{ Mean } & \multirow{2}{*}{ SD } & \multicolumn{3}{|c|}{$\begin{array}{l}\text { Extent of } \\
\text { perception }\end{array}$} & \multirow{2}{*}{ Mean } & \multirow{2}{*}{ SD } & \multicolumn{2}{|c|}{$\begin{array}{l}\text { Extent of } \\
\text { perception }\end{array}$} & \multirow[b]{2}{*}{ High } \\
\hline & & & Low & Medium & High & & & Low & Medium & \\
\hline $\begin{array}{l}\text { Excessive work load for the } \\
\text { existing nurses in terms of clerical } \\
\text { work, patient related work and } \\
\text { supportive work (VI) }\end{array}$ & 26.75 & 3.67 & 16.67 & 67.33 & 16 & 28.64 & 3.86 & 14 & 69 & 17 \\
\hline $\begin{array}{l}\text { Difficult to leave from the duty } \\
\text { on time (due to shortage of } \\
\text { manpower, the existing employees } \\
\text { have to do all work and hence } \\
\text { they have to leave duty very late) } \\
\text { (V2) }\end{array}$ & 26.66 & 3.53 & 21.67 & 54 & 24.33 & 28.53 & 3.73 & 22 & 61.67 & 16.33 \\
\hline $\begin{array}{l}\text { Often having health related } \\
\text { problems such as head ache, } \\
\text { tiredness, loss of energy and } \\
\text { weight loss because of the too } \\
\text { much work load (V3) }\end{array}$ & 26.12 & 3 & 20 & 60.67 & 19.33 & 26.64 & 3.04 & 61.33 & 21 & 17.67 \\
\hline $\begin{array}{l}\text { Inability to provide adequate } \\
\text { care and equal importance } \\
\text { for all patients. This leads to } \\
\text { dissatisfaction of the patients (V4) }\end{array}$ & 25.66 & 4.69 & 18.33 & 65.33 & 14.33 & 27.52 & 4.86 & 67.67 & 16.33 & 16 \\
\hline $\begin{array}{l}\text { Need to perform multiple works } \\
\text { at the same time because of } \\
\text { shortage of manpower.This results } \\
\text { in inaccuracy in the work (V5) }\end{array}$ & 25.55 & 4.81 & 15 & 69 & 16 & 28.48 & 4.93 & 19.67 & 57 & 23.33 \\
\hline $\begin{array}{l}\text { Often having conflict and dispute } \\
\text { with co-workers and other } \\
\text { departmental workers because } \\
\text { of stress and thereby inability to } \\
\text { complete the work in time (V6) }\end{array}$ & 25.48 & 4.52 & 16.67 & 69 & 14.33 & 25.36 & 4.13 & 19 & 60.67 & 18.33 \\
\hline $\begin{array}{l}\text { Low sense of commitment } \\
\text { and morale among the existing } \\
\text { employees (V7) }\end{array}$ & 15.18 & 4.25 & 11.67 & 69 & 19.33 & 15.34 & 4.36 & 16.33 & 67.33 & 14.33 \\
\hline $\begin{array}{l}\text { Facing interruption in daily work } \\
\text { flow (such as transferring the } \\
\text { patient to operation theatre, } \\
\text { ICU and wards) because of the } \\
\text { shortage of manpower (V8) }\end{array}$ & 19.05 & 4.21 & 20 & 67.33 & 12.67 & 21.36 & 4.63 & 14 & 70 & 15 \\
\hline $\begin{array}{l}\text { Loss of interest and dissatisfaction } \\
\text { in the job because of too much } \\
\text { work load and this lead to develop } \\
\text { thought of availing leave for duty } \\
\text { and take rest in house (V9) }\end{array}$ & 19 & 4.19 & 19.33 & 70 & 10.67 & 22.34 & 4.53 & 15.67 & 70 & 13.33 \\
\hline
\end{tabular}


Table Continued.

Multi-Speciality

Hospitals
Single Speciality Hospitals

Employee performance

\begin{tabular}{|c|c|c|c|c|c|c|c|c|c|}
\hline \multirow[t]{2}{*}{ Mean } & \multirow[t]{2}{*}{ SD } & \multicolumn{3}{|c|}{$\begin{array}{l}\text { Extent of } \\
\text { perception }\end{array}$} & \multirow[t]{2}{*}{ Mean } & \multirow[t]{2}{*}{ SD } & \multicolumn{3}{|c|}{$\begin{array}{l}\text { Extent of } \\
\text { perception }\end{array}$} \\
\hline & & Low & Medium & High & & & Low & Medium & High \\
\hline
\end{tabular}

Inability to complete daily routines and procedures on time and make delay and it makes doctors and other higher officials criticizing

existing nurses (VIO)

Inability to segregate biomedical wastes according to the rules because of stress and urgency work nature. This tends to receiving complaints from housekeeping and biomedical department (VII)

Inability to use the resources fully and also wasting resources as newly joined staff will take time to learn routines thoroughly (VI2)

Inability to provide adequate information to the doctors and surgeons about the patients and their conditions because of forgetfulness and nervous (VI3)

Inability to take decision and solve problems that arises suddenly because of too much work load and stress (VI4)

Often facing minor injuries (such as needle stick injuries) because of high work load, stress and tiredness (VI5)

Disturbed flow of work and it affects safety of the patients (VI6)

High level of stress as existing nurses should carry out the duties of left nurses until new nurses are appointed in the department and those newly appointed nurses to learn their routine work (VI7)

Inability to plan daily work and proceed according to the plan (VI8)

Inability to complete the work perfectly and keep work pending. This leads the patients dissatisfied 
Table Continued..

\begin{tabular}{|c|c|c|c|c|c|c|c|c|c|c|}
\hline \multirow{3}{*}{ Employee performance } & \multicolumn{5}{|c|}{$\begin{array}{l}\text { Multi-Speciality } \\
\text { Hospitals }\end{array}$} & \multicolumn{5}{|c|}{ Single Speciality Hospitals } \\
\hline & \multirow[t]{2}{*}{ Mean } & \multirow[t]{2}{*}{ SD } & \multicolumn{3}{|c|}{$\begin{array}{l}\text { Extent of } \\
\text { perception }\end{array}$} & \multirow[t]{2}{*}{ Mean } & \multirow[t]{2}{*}{ SD } & \multicolumn{3}{|c|}{$\begin{array}{l}\text { Extent of } \\
\text { perception }\end{array}$} \\
\hline & & & Low & Medium & High & & & Low & Medium & High \\
\hline $\begin{array}{l}\text { Lack of efficiency in the work } \\
\text { because of more work load and it } \\
\text { will be lasting until new nurses are } \\
\text { recruited and they get fully trained } \\
\text { (V20) }\end{array}$ & 19.16 & 3.15 & 20 & 61.67 & 18.33 & 19.22 & 3.18 & 16.33 & 68.33 & 15.33 \\
\hline $\begin{array}{l}\text { Inability to maintain and manage } \\
\text { various medical equipments } \\
\text { properly and safely because of } \\
\text { hurriedness (new staffs would also } \\
\text { take long time to learn about the } \\
\text { equipments) (V2I) }\end{array}$ & 19.39 & 3.55 & 16 & 66.67 & 17.33 & 22.28 & 4.13 & 10.67 & 71 & 18.33 \\
\hline $\begin{array}{l}\text { Inability to maintain inventory } \\
\text { accurately and to keep the } \\
\text { things in order and also inability } \\
\text { to control missing of things in } \\
\text { department (V22) }\end{array}$ & 20.36 & 3.58 & 17 & 62.33 & 18.67 & 21.62 & 4.13 & 16.33 & 68.33 & 15.33 \\
\hline $\begin{array}{l}\text { Inability to provide the patients } \\
\text { adequate information about their } \\
\text { treatment protocols and clarify } \\
\text { their doubts clearly because of } \\
\text { hurriedness in the work (V23) }\end{array}$ & 22.68 & 3.83 & 12.33 & 72.67 & 15 & 24.72 & 3.95 & 15 & 69.33 & 15.67 \\
\hline $\begin{array}{l}\text { Inability to maintain smooth } \\
\text { relationship with the patients, } \\
\text { their relatives and other staffs. } \\
\text { Often exhibiting irritation and } \\
\text { anger towards them because } \\
\text { of the much work load and too } \\
\text { much stress (V24) }\end{array}$ & 20.54 & 3.79 & 17.33 & 67.33 & 13.33 & 20.76 & 3.84 & 20.67 & 56 & 23.33 \\
\hline $\begin{array}{l}\text { Inability to complete record work } \\
\text { and treatment protocols fully and } \\
\text { commit errors in them because } \\
\text { of urgency and hurry up nature } \\
\text { (V25) }\end{array}$ & 19.34 & 3.17 & 17.33 & 66.67 & 16 & 20.67 & 3.56 & 18 & 64.67 & 17.33 \\
\hline
\end{tabular}

Source Computed from primary data

It could be figured out from Table 2 that the nurses working in both multi-speciality and single speciality hospitals have shown equal perception towards the factors, health related problems (V3),conflict and dispute with co-workers and other departmental workers (V6), low sense of commitment and morale among the existing employees (V17), inability to complete daily routines and procedures on time (V10), inability to use the resources fully and also wasting resources (V12), inability to plan daily work and proceed according to the plan (V18), inability to complete the work perfectly and keep work pending (V19), lack of efficiency in the work (V20), inability to maintain smooth relationship with the patients, their relatives and other staffs (V24), inability to complete record work and treatment protocols fully and commit errors (V25) have been equally perceived by nurses working in multi-speciality and single speciality hospitals. It is common to be affected with health related problems when work load is increasing. Moreover, when the vacant positions are not filled for longer period of time, it will affect satisfaction of the patients leading to diminishing organizational commitment and morale of the employees towards the organization. Health related problem such as stress and frustration will make the employees tiredness causing them not to complete the work perfectly and make errors in the work processes which will further impact on satisfaction and safety of the patients.

It could be observed from Table 3 that the perception of married nurses working in both multi and single speciality hospitals is high 
towards health related problems such as head ache, tiredness, loss of energy and weight loss (V3)than unmarried nurses. When compared to unmarried nurses, the nurses of married and those who have children have more work in their house rather than unmarried nurses. They have to look after husband, children and elders in the family in addition to house work. With these work, whey they need to do additional work of left employees, definitely they will have health related issues. At the same time, nurses of above 35 years in both kinds of hospitals have shown higher perception towards health related factors than nurses of less than 35 years of age. Aging process may not be able to cope with too much work load which arises as a result of lack of manpower. Perception of nurses of unmarried is higher towards the factors, loss of interest and dissatisfaction in the job (V9) and inability to maintain smooth relationship with the patients, their relatives and other staffs (V24) rather than unmarried nurses. As far as educational qualification is concerned, the perception of nurses qualified with B.Sc nursing and DGNM is equal. From this equality, it could be understood the employee turnover of nurses has impacted both of them equally in both kinds of hospitals. It could also be noted from Table 3 that nurses of below 30 years of age working in both kinds of hospitals have shown high perception towards high level of stress (V17), inability to plan daily work and proceed according to the plan (V18), inability to complete the work perfectly and keep work pending (V19), lack of efficiency in the work (V20), inability to maintain and manage various medical equipments properly and safely (V21), inability to maintain inventory accurately and to keep the things in order, and also inability to control missing of things in department (V22), inability to provide the patients adequate information about their treatment protocols and clarify their doubts clearly (V23), inability to maintain smooth relationship with the patients, their relatives and other staffs and inability to complete record work and treatment protocols fully and commit errors in them (V24) than nurses of above 30 years of age. The reason for these variations may be the maturity level and the experience in the life. As the age increases, the maturity level of the employees grows and they learn to confront the difficulties taking place in the life including financial needs and family demands (Table 4). It could be figured out that nurses who work in both kinds of hospitals and have less than 2 years of work experience and receive salary of less than Rs. 8000 have shown the highest perception towards the factors, excessive work load for the existing nurses (V1), performing multiple works at the same time (V5), conflict and dispute with co-workers and other departmental workers (V6), inability to provide adequate information to the doctors and surgeons about the patients and their conditions (V13) getting minor injuries (V15) and inability to take decision and solve problems that arises suddenly (V14).The reason for higher perception towards these factors may be that when compared to the experienced nurses, those who have less experience feel hard to carry out more work which occurs as a result of lack of manpower in the department. They often get stress, frustration to do too much work which cause them forgetfulness and emotional instability. The less salary provided to them also make them dissatisfied with the work. As a result, they quarrel with co-workers and workers in other department and they are not able to complete the work perfectly and completely.

Table 3 Comparative analysis of perception based on demographic variables (Marital status, educational qualification and age)

\begin{tabular}{|c|c|c|c|c|c|c|c|c|c|c|c|c|c|c|c|c|}
\hline \multirow{4}{*}{ Factors } & \multicolumn{4}{|c|}{ Marital status } & \multicolumn{4}{|c|}{ Educational qualification } & \multicolumn{8}{|c|}{ Age (Years) } \\
\hline & \multicolumn{2}{|c|}{ Multi } & \multicolumn{2}{|c|}{ Single } & \multicolumn{2}{|c|}{ Multi } & \multicolumn{2}{|c|}{ Single } & \multicolumn{4}{|c|}{ Multi } & \multicolumn{4}{|c|}{ Single } \\
\hline & Mar & Unm & Mar & Unm & B.Sc & DGNM & B.Sc & DGNM & $<25$ & $25-30$ & $30-35$ & $>35$ & $<25$ & $25-30$ & $30-35$ & $>35$ \\
\hline & Mean & Mean & Mean & Mean & Mean & Mean & Mean & Mean & Mean & Mean & Mean & Mean & Mean & Mean & Mean & Mean \\
\hline $\mathrm{V} 1$ & 26.47 & 26.55 & 25.73 & 24.28 & 26.86 & 25.48 & 24.56 & 24.38 & 26.74 & 26.54 & 25.34 & 26.75 & 26.15 & 26.68 & 25.14 & 25.27 \\
\hline $\mathrm{V} 2$ & 27.63 & 27.65 & 27.59 & 27.09 & 22.57 & 22.60 & 22.54 & 22.49 & 27.60 & 27.65 & 27.67 & 27.63 & 27.54 & 27.48 & 26.88 & 27.58 \\
\hline V3 & 24.66 & 28.68 & 23.62 & 27.12 & 22.40 & 22.43 & 22.37 & 22.32 & 22.47 & 22.52 & 23.54 & 28.05 & 23.41 & 22.35 & 23.75 & 27.45 \\
\hline $\mathrm{V} 4$ & 26.12 & 26.14 & 26.08 & 25.58 & 21.28 & 21.31 & 21.25 & 21.27 & 25.76 & 25.81 & 25.83 & 25.79 & 25.70 & 25.64 & 25.04 & 25.74 \\
\hline V5 & 25.66 & 25.68 & 25.62 & 25.12 & 21.01 & 21.04 & 20.98 & 20.93 & 25.62 & 25.67 & 25.69 & 25.65 & 25.56 & 25.58 & 24.9 & 25.60 \\
\hline V6 & 25.55 & 25.57 & 25.51 & 25.01 & 20.05 & 20.08 & 20.02 & 19.97 & 25.46 & 25.51 & 25.53 & 25.49 & 25.40 & 25.34 & 24.74 & 25.44 \\
\hline V7 & 25.48 & 25.58 & 25.44 & 24.94 & 20.02 & 20.05 & 19.99 & 19.94 & 25.43 & 25.48 & 25.50 & 25.46 & 25.37 & 25.31 & 24.71 & 25.41 \\
\hline V8 & 24.66 & 24.68 & 24.62 & 24.12 & 19.94 & 19.97 & 19.91 & 19.86 & 22.56 & 22.61 & 22.63 & 22.59 & 22.50 & 22.44 & 21.84 & 22.54 \\
\hline $\mathrm{V} 10$ & 22.73 & 22.75 & 22.69 & 22.19 & 19.78 & 19.81 & 19.75 & 19.75 & 22.63 & 22.68 & 22.73 & 22.66 & 22.57 & 22.51 & 21.91 & 22.61 \\
\hline V11 & 22.06 & 22.09 & 22.02 & 21.52 & 22.57 & 22.63 & 22.54 & 22.49 & 22.03 & 22.08 & 22.15 & 22.06 & 21.97 & 21.91 & 21.31 & 22.01 \\
\hline V12 & 21.73 & 21.76 & 21.69 & 21.19 & 22.48 & 22.51 & 22.45 & 22.43 & 19.68 & 19.73 & 19.75 & 19.71 & 19.62 & 19.56 & 18.96 & 19.66 \\
\hline V13 & 21.68 & 21.71 & 21.64 & 21.14 & 22.43 & 22.47 & 22.47 & 22.35 & 20.54 & 20.59 & 20.61 & 20.57 & 20.48 & 20.42 & 19.82 & 20.52 \\
\hline V14 & 21.51 & 21.54 & 21.50 & 21.21 & 22.26 & 22.34 & 22.28 & 22.23 & 18.23 & 18.28 & 18.34 & 18.26 & 18.17 & 18.11 & 17.51 & 18.21 \\
\hline V15 & 20.39 & 20.42 & 20.38 & 19.88 & 21.14 & 21.18 & 21.16 & 21.12 & 20.13 & 20.16 & 20.15 & 20.10 & 20.07 & 20.01 & 19.41 & 19.46 \\
\hline V16 & 20.12 & 20.15 & 20.11 & 19.71 & 20.87 & 20.91 & 20.89 & 20.85 & 18.71 & 18.74 & 18.73 & 18.68 & 18.65 & 18.59 & 17.99 & 18.04 \\
\hline V17 & 19.16 & 19.19 & 19.15 & 18.75 & 19.91 & 19.95 & 19.93 & 19.89 & 26.11 & 24.14 & 19.13 & 19.08 & 27.05 & 26.99 & 18.39 & 18.44 \\
\hline V18 & 19.13 & 19.16 & 19.12 & 18.72 & 19.88 & 19.92 & 19.98 & 19.86 & 25.03 & 24.06 & 19.05 & 19.58 & 26.97 & 28.91 & 18.31 & 18.36 \\
\hline V19 & 19.05 & 19.08 & 19.04 & 18.64 & 19.89 & 19.84 & 19.82 & 19.78 & 27.97 & 28.24 & 18.99 & 18.94 & 27.91 & 28.85 & 18.25 & 18.30 \\
\hline V20 & 19.00 & 19.03 & 18.99 & 18.59 & 19.75 & 19.79 & 19.77 & 19.73 & 26.87 & 28.93 & 18.89 & 18.84 & 24.81 & 25.75 & 18.15 & 18.20 \\
\hline
\end{tabular}


Table Continued..

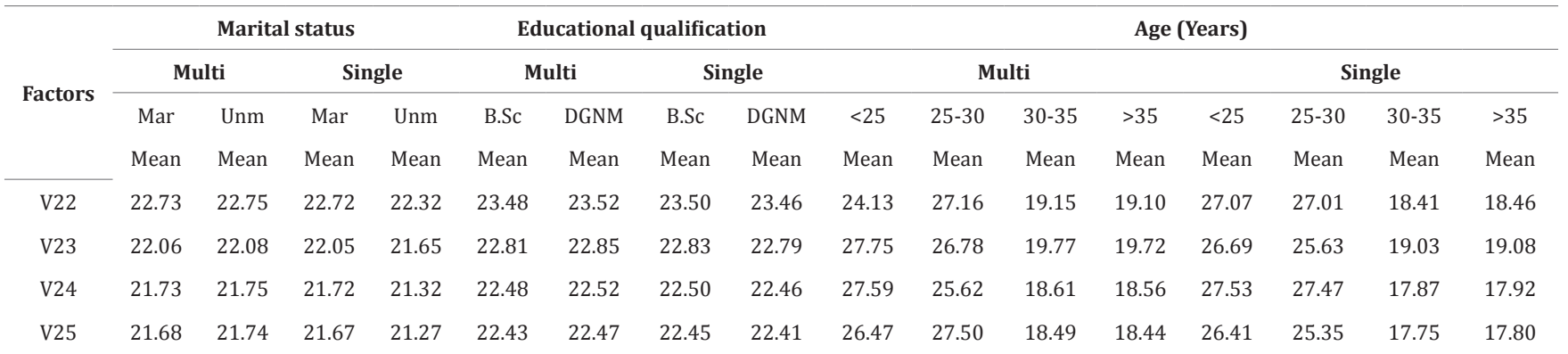

Table 4 Comparative analysis of perception based on demographic variables (Work experience and salary)

\begin{tabular}{|c|c|c|c|c|c|c|c|c|c|c|c|c|c|c|c|c|}
\hline \multirow{4}{*}{ Factors } & \multicolumn{8}{|c|}{ Work Experience } & \multicolumn{8}{|c|}{ Salary (Rs) } \\
\hline & \multicolumn{4}{|c|}{ Multi } & \multicolumn{4}{|c|}{ Single } & \multicolumn{4}{|c|}{ Multi } & \multicolumn{4}{|c|}{ Single } \\
\hline & $<2$ & $2-4$ & $4-6$ & $>6$ & $<2$ & $2-4$ & $4-6$ & $>6$ & $<6000$ & $\begin{array}{c}6000- \\
8000\end{array}$ & $\begin{array}{l}8000- \\
10000\end{array}$ & $>10000$ & $<6000$ & $\begin{array}{c}6000- \\
8000\end{array}$ & $\begin{array}{l}8000- \\
10000\end{array}$ & $>10000$ \\
\hline & Mean & Mean & Mean & Mean & Mean & Mean & Mean & Mean & Mean & Mean & Mean & Mean & Mean & Mean & Mean & Mean \\
\hline $\mathrm{V} 1$ & 28.74 & 24.76 & 24.79 & 24.73 & 28.66 & 23.69 & 24.64 & 23.61 & 27.67 & 27.68 & 22.71 & 21.65 & 27.75 & 27.76 & 21.72 & 20.69 \\
\hline V2 & 25.60 & 25.62 & 25.65 & 25.59 & 26.53 & 26.56 & 26.51 & 26.48 & 26.54 & 26.55 & 26.58 & 26.52 & 26.62 & 26.63 & 26.59 & 26.56 \\
\hline V3 & 25.44 & 25.46 & 25.49 & 25.43 & 25.82 & 25.85 & 25.80 & 25.77 & 25.83 & 25.84 & 25.87 & 25.81 & 25.91 & 25.92 & 25.88 & 25.85 \\
\hline $\mathrm{V} 4$ & 25.41 & 25.43 & 25.46 & 25.40 & 25.68 & 25.71 & 25.66 & 25.63 & 25.69 & 25.70 & 25.73 & 25.67 & 25.77 & 25.78 & 25.74 & 25.71 \\
\hline V5 & 22.54 & 22.56 & 22.59 & 22.53 & 25.52 & 25.55 & 25.50 & 25.47 & 27.53 & 28.54 & 20.57 & 19.51 & 27.61 & 28.62 & 18.58 & 20.55 \\
\hline V6 & 27.95 & 22.97 & 23.00 & 22.94 & 28.49 & 25.52 & 25.47 & 25.44 & 27.50 & 27.51 & 18.54 & 19.48 & 25.58 & 28.59 & 20.55 & 18.52 \\
\hline V7 & 22.61 & 22.63 & 22.66 & 22.60 & 22.62 & 22.65 & 22.60 & 22.57 & 22.63 & 22.64 & 22.67 & 22.61 & 22.71 & 22.72 & 22.68 & 22.65 \\
\hline V8 & 22.01 & 22.03 & 22.06 & 22.00 & 23.03 & 23.06 & 23.01 & 22.98 & 23.04 & 23.05 & 23.08 & 23.02 & 23.12 & 23.13 & 23.09 & 23.06 \\
\hline V9 & 19.66 & 19.68 & 19.71 & 19.65 & 22.69 & 22.72 & 22.67 & 22.64 & 22.70 & 22.71 & 22.74 & 22.68 & 22.78 & 22.79 & 22.75 & 22.72 \\
\hline V10 & 20.52 & 20.54 & 20.57 & 20.51 & 22.09 & 22.12 & 22.07 & 22.04 & 22.10 & 22.11 & 22.14 & 22.08 & 22.18 & 22.19 & 22.15 & 22.12 \\
\hline V11 & 18.21 & 18.23 & 18.26 & 18.20 & 19.74 & 19.77 & 19.72 & 19.69 & 19.75 & 19.76 & 19.79 & 19.73 & 19.83 & 19.84 & 19.80 & 19.77 \\
\hline V12 & 20.11 & 20.15 & 20.16 & 20.10 & 20.60 & 20.63 & 20.58 & 20.55 & 20.61 & 20.62 & 20.65 & 20.59 & 20.69 & 20.70 & 20.66 & 20.63 \\
\hline V13 & 24.69 & 20.71 & 20.74 & 20.68 & 24.29 & 18.32 & 18.27 & 18.24 & 28.30 & 28.31 & 18.34 & 20.28 & 27.38 & 28.39 & 20.35 & 19.32 \\
\hline V14 & 25.09 & 21.11 & 21.14 & 21.08 & 25.19 & 20.22 & 20.17 & 20.14 & 28.20 & 27.23 & 20.24 & 20.18 & 28.28 & 27.29 & 19.25 & 20.22 \\
\hline V15 & 27.01 & 21.03 & 21.06 & 21.00 & 25.77 & 20.80 & 20.75 & 20.72 & 27.78 & 26.79 & 20.82 & 19.76 & 27.86 & 27.87 & 19.83 & 20.80 \\
\hline V16 & 20.95 & 20.97 & 21.00 & 20.94 & 21.17 & 21.20 & 21.15 & 21.12 & 21.18 & 21.19 & 21.22 & 21.16 & 21.26 & 21.27 & 21.23 & 21.20 \\
\hline V17 & 20.85 & 20.87 & 20.90 & 20.84 & 21.09 & 21.12 & 21.07 & 21.04 & 21.10 & 21.11 & 21.14 & 21.08 & 21.18 & 21.19 & 21.15 & 21.12 \\
\hline V18 & 26.74 & 20.76 & 20.79 & 20.73 & 26.03 & 21.06 & 21.01 & 20.98 & 27.04 & 25.05 & 21.08 & 20.02 & 28.12 & 27.13 & 19.09 & 20.06 \\
\hline V19 & 26.11 & 21.13 & 21.16 & 21.10 & 25.93 & 20.96 & 20.91 & 20.88 & 28.94 & 27.95 & 19.98 & 20.92 & 28.02 & 27.03 & 20.99 & 19.96 \\
\hline V20 & 27.73 & 21.75 & 21.78 & 21.72 & 26.82 & 20.85 & 20.80 & 20.77 & 27.83 & 28.84 & 20.87 & 19.81 & 28.91 & 27.92 & 19.88 & 18.85 \\
\hline V21 & 25.57 & 20.59 & 20.62 & 20.56 & 25.19 & 21.22 & 21.17 & 21.14 & 27.20 & 28.21 & 19.24 & 20.18 & 26.28 & 27.29 & 18.25 & 20.22 \\
\hline V22 & 28.45 & 20.47 & 20.50 & 20.44 & 26.81 & 21.84 & 21.79 & 21.76 & 26.82 & 26.83 & 19.86 & 18.80 & 27.90 & 27.91 & 18.87 & 19.84 \\
\hline V23 & 27.58 & 23.60 & 22.63 & 21.57 & 27.65 & 20.68 & 20.63 & 20.60 & 28.66 & 27.67 & 20.70 & 19.64 & 28.74 & 28.75 & 21.71 & 20.68 \\
\hline V24 & 26.74 & 22.76 & 22.79 & 23.73 & 27.66 & 23.69 & 20.64 & 21.61 & 28.54 & 26.55 & 19.58 & 19.52 & 27.62 & 27.63 & 19.59 & 19.56 \\
\hline V25 & 28.60 & 25.62 & 25.65 & 25.59 & 28.53 & 22.56 & 22.51 & 23.48 & 28.67 & 27.98 & 20.71 & 20.65 & 27.75 & 26.57 & 18.72 & 19.69 \\
\hline
\end{tabular}

Source Computed from primary data

Citation: Rajan D. Employee turnover and employee performance: a comparative study among nurses. MOJ App Bio Biomech. 20 I7; I(5):I6I-I73. 
Moreover, nurses of less than 2 years of work experiences and receive the salary of less than Rs. 8000 have also shown high perception towards the factors, inability to plan daily work and proceed according to the plan (V18), inability to complete the work perfectly and keep work pending, lack of efficiency in the work (V20), inability to maintain and manage various medical equipments properly and safely (V21), inability to maintain inventory accurately and to keep the things in order and also inability to control missing of things in department (V22), inability to provide the patients adequate information about their treatment protocols and clarify their doubts clearly because of hurriedness in the work (V23), inability to maintain smooth relationship with the patients, their relatives and other staffs, irritation and anger towards them (V24) and inability to complete record work and treatment protocols fully and commit errors in them because of urgency and hurry up nature (V25). In most of the hospitals, junior nurses look after inventory management medical equipments maintenance in the department. As junior nurses are responsible for these tasks, they are more prone to make mistakes when they are put in the situation of doing additional work when there is lack of manpower in the department. At the same time, when senior nurses are on leave, the junior nurses need to attend rounds with doctors. In the state of lack of manpower in the department, when the junior nurses need to look after the main tasks of the department, they struggle to plan the work and execute it.In the absence of senior nurses, when junior nurses need to attend rounds with the doctors, because of too much work load, they forget to give sufficient information about history and treatment protocols being followed which will further affect safety of the patients. Their lack of experience makes them developing high stress and frustration causing them to get minor injuries such as accidents and needle stick injuries. Moreover, their too much stress makes them to get conflict and dispute with co-workers, superiors and other departmental workers which will further delay the treatment procedures given to the patients questioning their safety. Naturally, patients and their relatives frequently ask nurses questions about their health, medicines and other information related to their treatment. When nurses work with lack of manpower, they cannot give information adequately rightly. This will also make the patients dissatisfied.

\section{Discussion}

The present research has found that employee turnover increased work load of the existing employees. This result is providing support to the study of Becker et al..$^{21}$ who observed that departure of one staff may lead to errors in the work performed by those taking over. He has also observed that it may happen either because the one taking over lacks the requisite skills to perform the job or is overburdened by work in his or her substantive position. The result of the present research has also found that employee turnover will cause more work load to the existing employees and also cause them committing error in the report. This result is corroborated with the study of Butali et al. ${ }^{22}$ who advocated that reduced number of employees in an organization increases the work for the remaining staff. According to the findings of this study, the increase in the workload overburdens the remaining staff and therefore can lead to serious errors being made due to overwork. The findings of the present study indicate that turnover increases the work load of remaining nurses. This result is in par with the study of Shamian J et al..$^{23}$ (2001) who proved that more than one-third of nurses got high emotional exhaustion, had higher overall and musculo-skeletal claim rates when compared to non-nurses and musculo-skeletal claims comprised the majority of nursing claims.
The present research has found that employee turnover maximises work load among existing nurses and that will further produce minor injuries in the work place. This finding is corroborated with the study of Clarke et al. ${ }^{24}$ who observed that poor organizational climate and high workloads are associated with needle stick injuries. The result of the present study has pointed out that employee turnover affects the morale of remaining nurses. This finding is supporting the study of 25 . Warren $\mathrm{S}^{25}$ who pointed out that high turnover will cause poor morale among the employees and also affect the level of productivity efficiency.

The present research has found that employee turnover affect interest and satisfaction of the employees. This research provide support for the evidence of Gawali $\mathrm{V},{ }^{26}$ who proved that employee turnover typically causes lack of motivation and low morale and enthusiasm. The present research has found that employee turnover affect commitment and morale of the existing employees because of too much work load and health related problems. This result is consistent with the study of WeiBo. Who proved that labour turnover is costly, lowers productivity, kills morale, losses customers to competitors and tends to get worse if it is not urgently addressed, hence, constitutes challenges.

\section{Suggestion and conclusion}

\section{Suggestions}

The researcher presents the following suggestions to prevent employee turnover of nurses and to retain the existing nurses in the hospitals for long time.

A. The management should take necessary steps to prevent employee turnover in a serious way. By means of selecting suitable employees, providing appropriate training, job enrichment, normal working hours, healthy shift schedule and department allocation, decent salary, increment, reward, professional respect, motivation and welfare facilities, the employee turnover can be reduced and prevented.

B. Vacancy positions should be filled with immediate effect without any delay so as to enable smooth functioning of the department. If the hospital makes any delay due to delay in finding suitable nurses the management should compensate to the existing nurses who is carrying out the functions of the nurses who left. In addition to monetary compensation, psychological support should be given in the form of motivation until the vacancy position is filled.

C. Adequate number of nursing assistants and other supportive staffs such as ward secretaries and trainees should be appointed for smooth work flow in the department and reduce the work burden of the department. Nurses of less experienced and less aged should be educated that they should learn to cope up with critical and emergency situations that take place unexpectedly in order to enhance their skills and abilities and thereby advance their career development.

\section{Limitations of the study}

The study confined to Tirunelveli city only and it has not covered the entire district. The study has focused the nurses qualified with Diploma in General Nursing and Midwifery (DGNM) and Bachelor of Science in Nursing working in private multi-speciality and single speciality hospitals and it has not studied the nurses qualified with any other courses such as Diploma in Nursing Assistants and Master 
of Science in Nursing. The study has not focused nurses working in government hospitals and any other health care institutions such as diagnostic centres. Moreover, this study has not included any other group of professionals in the hospitals such as doctors, managers, receptionists, pharmacists, radiographers, medical laboratory technicians and so on. As a result of these limitations, it is important to be cautious when generalising the results of this present research to the entire district and other occupational groups.

\section{Directions for future study}

This present research providesmultiple ways to carry out future research studies. The present research can be extended into entire district. Other categories of nurses such as nurses qualified with Diploma in Nursing Assistants and Master of Science in Nursing can also be included in future study. The future research can also be undertaken covering the nurses working in government hospitals and other health care institutions. The future research can also be undertaken as comparative study adding the nurses working in government hospitals other health care institutions.

\section{Conclusion}

This descriptive research undertaken in Tirunelveli city, Tamilnadu analysed and differentiated perception of the nurses working in multi-speciality and single speciality hospitals towards the impact of employee turnover on performance of the existing nurses from the sample of 120 nurses (60 from multi and 60 from single speciality hospitals) qualified with Diploma in General Nursing and Midwifery (DGNM) and Bachelor in Nursing (B.Sc Nursing) courses using judgement sampling technique. The results of the study proved that nurses working in single speciality hospitals have shown significant higher perception towards work load, work time, loss of interest, work stress and inability to provide information than multi-speciality hospitals. Nurses working in both kinds of hospitals have shown equal perception towards health related problems, conflict and dispute, sense of commitment and morale. Nurses who working in both kinds of hospitals with the profile of married, less than 30 years of age, drawing less than Rs. 8000 salary and having less than 2 years of work experience had highly perceived that employee turnover impacted performance of existing nurses. Nursing, practice based activity, has a dynamic role in promoting, maintaining and restoring health of the patients. Presence of adequate nurses with right mixture is mandatory to give quality care to the patients and maintain good health of the nurses. High rate of employee turnover of nurses would not only affect health, family and social life of the existing nurses, but also impact quality of the nursing care and safety of the patients negatively. Hence, great attention is needed to retain nurses for prolonged time so as to ensure quality of the nursing care and safety of the patients.

\section{Acknowledgments}

None.

\section{Conflicts of interest}

Author declares that there is no conflict of interest.

\section{References}

1. Mohsen N. Leadership from the Quran relationship between Taqwa, trust and business leadership effectiveness. University of Malaysia, Malaysia; 2007.
2. Lau S, Albright L. Positive turnover, disability awareness, employee selection guidelines. HR Magazine. 2001;56(1):20-21.

3. WeiBo Z, Kaur S, Zhi T. A critical review of employee turnover model and development in perspective of performance. African journal of business management. 2010;4(19):4146-4158.

4. Price J. Reflections on the Determinants of Voluntary Turnover. International Journal of Manpower. 2001;22(7):600-624.

5. Price JL. The Study of Turnover. Administrative Science Quarterly. 1977;23(2):351-353

6. Thwala DW, Ajagbe AM, Long CS, et al. Sudanese Small and Medium Sized Construction Firms: An Empirical Survey of Job Turnover. Journal of Basic and Applied Social Research. 2012;2(3):24-32.

7. Currivan DB. The Casual Order of Job Satisfaction and Organizational Commitments in Models of Employee Turnover. Human Resources Management Review. 1999;9(4):495-524.

8. Agnes M. Webster's New World College Dictionary. 4th ed. New York: Macmillan; 1999.

9. Rajan D. Analysis of Push and Pull Factors in Turnover of Nurses. International Journal of Management. 2014;3(5):26-40.

10. Namasaka David B, Poipoi Moses W, Lausa Cathrine M. Effects of Staff Turnover on the Employee Performance of work at Masinde Muliro University of Science and Techoogy. International Journal of Human Resource Studies. 2013;3(1):1-8.

11. Rajan D. Impact of Nurses Turnover on Organization Performance. Afro Asian Journal of Social Sciences. 2013;4(4):1-18.

12. Santript S, Ambalika S. Employee Turnover in Banking Sector: Empirical Evidence. IOSR Journal of Humanities and Social Science. 2013;11(5):57-61.

13. Jhatial AA, Riaz Ahmed M, Ikhtiar Ali G. Antecedents and Consequences of Employee Turnover: Empirical Evidence from Pakistan. British Journal of Economics, Management and Trade. 2012;2(4):279-295.

14. Kuriya S, Ondigi A. Assessment of Causes of Labour Turnover in Three and Five Star Hotels in Kenya. International Journal of Business and Social Science. 2012;3(15):311-317.

15. Abdali F. Impact of Employee Turnover on Sustainable Growth of Organization in Computer Graphics Sector of Karachi, Pakistan. Afro Asian Journal of Social Sciences. 2011;2(2.4):1-24.

16. Chalkiti K, Marianna S. Staff Turnover in the Greek Tourism Industry. International Journal of Contemporary Hospitality Management. 2010;22(3):335-359.

17. Shah IA, Zainab F, Shakil Ahmad M, et al. Measuring Push, Pull and Personal Factors Affecting Turnover Intention: A Case of University Teachers in Pakistan. Review of Economic and Business Studies. 2010;3(1):167-192.

18. Kayuni H, Richard T. Teacher Turnover in Malawi's Ministry of Education: Realities and Challenges. International Education Journal. 2007;8(1):89-99.

19. Ramball S. Managing Employee Retention as a Strategy for Increasing Organizational Competitiveness. Applied HRM Research. 2003;8(2):63-72.

20. Rajan D. Employee turnover and employee performance: A study among nurses. ANVESHAK: International journal of management. 2016;5(2):9-26.

21. Becker BE, Huselid MA, Pickus PS, et al. HR as a Source of Shareholder Value, Research and Recommendations. Human Resource Management. 1997;36(1):39-47. 
22. Butali ND, Wesangula PM, Mamuli LC. Effect of staff turnover on employee performance of the work at MasindeMulira University of Science and Technology. International Journal of Human Resource Studies. 2013;3(1):1-8.

23. Shamian J, Brien-Pallas L. Effects of Job Strain, Hospital Organizational Factors and Individual Characteristics on Work-Related Disability among Nurses. Final Report submitted to the Ontario Workplace Safety and Insurance Board. Canada; 2001.
24. Clarke SP, Rockett JL, Sloane DM, et al. Organizational Climate, Staffing and Safety Equipment as Predictors of Needle stick Injuries and Near-Misses in Hospital Nurses. Am J Infect Control. 2002;30(4):207-216.

25. Warren S. The Transient Workers. The Wall Street Journal. 2002;4.

26. Gawali V. Effectiveness of employee cross-training as a motivational technique. ASBM Journal of Management. 2009;2(2):138-146. 